\title{
7 ENSAIOS PARA UM ENSINO ESTÉTICO ${ }^{1}$
}

\author{
| Marcela Muniz ${ }^{2}$; Ana Abrahão ${ }^{3}$; Cláudia Tavares ${ }^{4}$; Flávio Alves ${ }^{5}$; Andrea Elias ${ }^{6}$; Luciana Higino ${ }^{7}$ |
}

\section{RESUMO}

CONTEXTO: Os processos de ensino-aprendizagem trazem marcas disciplinares e capitalísticas que o cerceiam. Isso implica na necessidade de restabelecer-se um debate crítico comprometido com um regime estético que busque enfrentar a disciplinarização e docilização dos corpos presentes nas práticas de ensino na saúde, nas quais as nuances da diferença continuam sendo vistas sob o ponto de vista de algo a ser corrigido e governado.

OBJETIVO(S): O presente estudo teve como objetivo realizar uma reflexão teórico-crítica a respeito dos espaços de formação que se têm configurado no âmbito do ensino em saúde.

METODOLOGIA: Utilizou-se como método a reflexão com base no referencial teórico-metodológico ético-estético.

RESULTADOS: Apesar da "tradição do novo" evocada pelos discursos atuais, vimos sustentando um modelo de ensino pragmático em saúde que ainda isola corpo sensível do estudante do corpo pensamento do estudante, bem como o corpo pensamento do professor do seu corpo sensível. É necessária a busca de pluralidade de afeç̧ões nas relações de ensino para que se promova a realização sensível de uma humanidade na formação em saúde.

CONCLUSÕES: Neste sentido, conclui-se que é necessário o investimento em dispositivos para a produção de um ensino em saúde comprometido com modos de vida livres, em seu sentido ético-estético.

PALAVRAS-CHAVE: Ensino; Instituições acadêmicas; Materiais de ensino

\section{RESUMEN}

\section{"Ensayos para una enseñanza estética"}

CONTEXTO: Los procesos de enseñanza-aprendizaje traen marcas disciplinarias y capitalistas capaces de limitar su alcance. Esto implica la necesidad de reestablecer un debate crítico comprometido con un régimen estético que busque afrontar la disciplinarización y docilización de los cuerpos presentes en las prácticas de enseñanza en salud, dónde los matices de diferencia siguen siendo percibidos como un detalle que debe ser corregido y gobernado.

OBJETIVO(S): El presente estudio tuvo como objetivo realizar una reflexión teórico-crítica acerca de los espacios de formación que han sido configurados en el ámbito de la enseñanza en salud.

METODOLOGÍA: Se utilizó como método la reflexión basada en el referencial teórico-crítico y ético-estético.

RESULTADOS: A pesar de la "tradición del nuevo" esgrimida por los discursos actuales, observamos el sostenimiento de un modelo de enseñanza en salud pragmático que aún aísla el cuerpo sensible del estudiante del cuerpo pensamiento del estudiante, así como el cuerpo pensamiento del enseñante de su cuerpo sensible. Se hace necesaria la búsqueda de la pluralidad de las afecciones en las relaciones de enseñanza para fomentar la realización sensible de una humanidad en la formación en salud.

CONCLUSIONES: En este sentido, se concluye que se hace necesaria la inversión en dispositivos para la producción de una enseñanza en salud comprometida con estilos de vida libres, en su sentido ético y estético.

\section{DESCRIPTORES: Enseñanza; Instituciones académicas; Mate- riales de enseñanza}

\begin{abstract}
"Aesthetic teaching trials"

BACKGROUND: The teaching-learning processes bear disciplinary and capitalistic marks that surround them. This entails the need to re-establish a critical debate committed to an aesthetic regime that seeks to deal with the disciplinarization and docilization of the bodies that feature health teaching practices, since the nuances of diversity are still viewed from the standpoint of something to be amended and governed.

AIM: This study was intended to accomplish a theoretical-critical reflection about the training fields that are being shaped in the scope of the health teaching.

METHODS: The reflection based on the ethical-esthetic and theoretical-critical framework was used as a method.

RESULTS: Despite the "tradition of the new" evoked by the current speeches, we have perceived the sustainment of a pragmatic health teaching model that still insulates the sensitive body of the student from his/her thinking body, as well as the thinking body of the teacher from his/her sensitive body. There is a need to seek plurality of affections in the teaching-related relationships in order to promote the sensitive achievement of humanity in the health training.

CONCLUSIONS: We have thus concluded that the investment in devices is necessary to produce a type of health teaching committed to free lifestyles, with regard to their ethical-esthetic meaning.
\end{abstract}

\section{KEYWORDS: Teaching; Academic institutions; Teaching mate- rials}

Submetido em 22-02-2016

Aceite em 30-05-2016

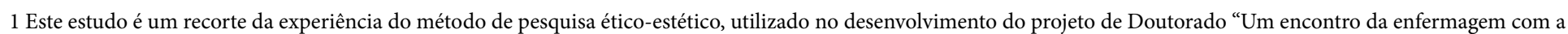

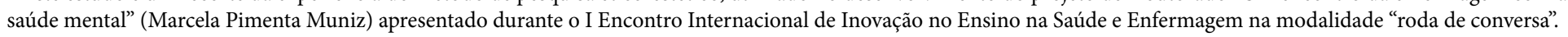

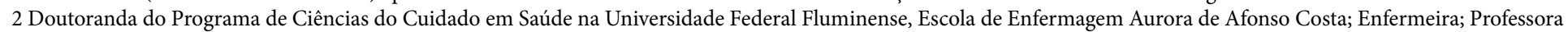
Assistente na Universidade Federal Fluminense, Escola de Enfermagem Aurora de Afonso Costa, Niterói, Brasil, marcelapimentamuniz@gmail.com

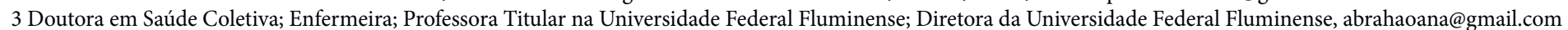
4 Pós-Doutora em Enfermagem; Enfermeira; Professora Titular na Universidade Federal Fluminense, Niterói, Brasil, claudiamarauff@gmail.com

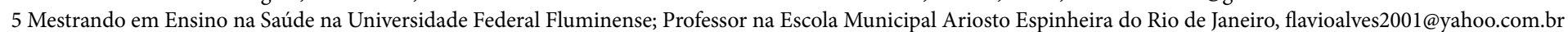

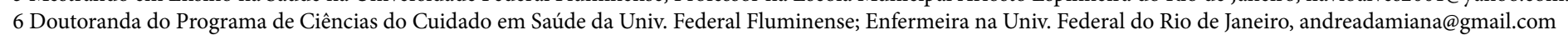

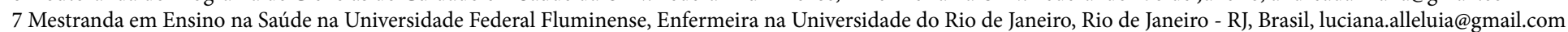

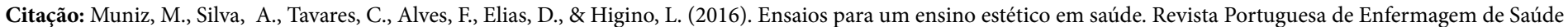
Mental (Spe. 4), 45-48. 


\section{INTRODUÇÃO}

O presente estudo aborda a temática do ensino, considerando-se a necessidade de restabelecer-se as condições de inteligibilidade para um debate crítico comprometido com um certo regime estético (Guattari e Rolnik, 1999) que busque enfrentar as marcas disciplinares e capitalísticas que cerceiam os processos de ensino-aprendizagem.

A disciplinarização e docilização dos corpos (Foucault, 2000) ainda está presente nas práticas de ensino na saúde, nas quais as nuances da diferença continuam sendo vistas sob o ponto de vista de algo a ser corrigido e governado. A "tecnologia" disciplinar do corpo constrói um sujeito com utilidade capitalista e docilidade e, não apenas, repressão e dominação. Isso se dá de modo discreto e sutil, para que não seja percebido, tornando a disciplina mais eficaz do que os métodos violentos. Destaca-se que a disciplina é "uma técnica de distribuição dos indivíduos através da inserção dos corpos em um espaço individualizado, classificatório, combinatório" (Foucault, 2000, p. 153). Trata-se de um mecanismo que propiciará uma transformação do sujeito, tirando da "força do corpo" sua "força política" e tornando máxima sua "força útil".

Desta forma, justifica-se a escolha do objeto de estudo pela necessidade de restabelecer-se as condições de inteligibilidade para um debate crítico comprometido com um ensino ético, que privilegie o sensível específico (Rancière, 2014) dos envolvidos em detrimento da totalização e docilização do sujeito.

O objetivo do estudo foi realizar uma reflexão teóricocrítica a respeito dos espaços de formação que se têm configurado no âmbito do ensino em saúde.

\section{METODOLOGIA}

Utilizou-se a reflexão com base no referencial teórico ético-estético. Considera-se que o regime estético está desobrigado de regras específicas ou de uma hierarquia de temas e gêneros (Rancière, 2014).

A noção Estética não é o rigor do domínio de um campo já dado (campo de saber), mas sim o da criação de um campo, que encarna as marcas no corpo do pensamento, como numa obra de arte. E o que se define como ético é a escuta às diferenças que se fazem nos envolvidos e se afirma o devir a partir dessas diferenças (Guattari e Rolnik, 1999).

\section{RESULTADOS E DISCUSSÃO}

As formações sociais contemporâneas, principalmente ocidentais, operam por modos de poder, que rebaixam a vida, que separam a vida do que ela pode produzir. As práticas de ensino, por sua vez, também têm sido governadas por esta lógica. $\mathrm{O}$ maior grau de autonomia que se consegue investir junto aos envolvidos é ensinar a obedecer, a seguir modos de viver que o atual regime capitalista considera serem os melhores.

Apesar da "tradição do novo" evocada pelos discursos atuais, vimos sustentando um modelo de ensino pragmático que ainda isola corpo sensível do estudante do corpo pensamento do estudante, bem como o corpo pensamento do professor do seu corpo sensível.

Os espaços de ensino estão, sobretudo, a serviço da disciplinarização e docilização dos estudantes e professores. Foucault (2000a) descreveu vários processos de disciplinarização dos corpos em diferentes instituições, como colégios, fábricas, oficinas, conventos e quartéis, demonstrando que a principal característica de tais instituições é a disciplina corporal. A operação moralizadora da disciplina institucional não atingiu só os corpos, mas também os próprios conhecimentos a serem ensinados.

Atualmente os sistemas de ensino propõem matérias e métodos de ensino a partir de um padrão que tem como critério algo que está fora dos próprios estudantes (ou até mesmo do professor), algo que não passa por eles. Estas práticas só suportam a vida em estado rebaixado e, nunca, intensivo. O que é intensivo no corpo e no pensamento não é tolerado, mesmo quando atualmente se diz "viva as diferenças" (que seria um modo farsante de resolver esse problema).

Então o que podem o estudante e o professor? Como eles podem-se reinventar no ensino a cada encontro? Inventa-se pelo que lhe afeta (e não quando se é indiferente), pelas conexões que estabelece ou as relações que se constroem.

Surge, nesta matiz, a possibilidade de linhas de fuga através de iniciativas que apostem em modos de vida implicados com uma ética em que as experiências no ensino estejam comprometidas consigo, a partir de experimentações de um ensino estético (Rancière, 2014). O objetivo dessas experimentações deve ser o de "formar homens capazes de viver numa comunidade política livre" (Rancière, 2014, p.39), através da realização sensível de uma comunidade comum. Na busca para a superação do paradigma disciplinar, acreditamos na necessidade da nossa própria reinvenção. 
A lógica disciplinar é uma "fábrica" de indivíduos, ela é a técnica específica de um poder que toma os indivíduos ao mesmo tempo como objetos e como instrumentos de seu exercício. Não é um poder triunfante que, a partir de seu próprio excesso, pode fiar-se em seu superpoderio, é um poder modesto, desconfiado, que funciona a modo de uma economia calculada, mas permanente. São humildes modalidades, procedimentos menores, se os compararmos aos rituais majestosos da soberania ou aos grandes aparelhos do Estado (Foucault, 2000a).

Neste sentido, aponta-se a passagem da sociedade disciplinar para a sociedade de controle, que busca a produção do novo sujeito moral, o sujeito flexível, tolerante e supostamente autônomo, visando fomentar a atitude autoempreendedora capaz de produzir o "capital humano" exigido pelos tempos que correm (Foucault, 2000b). Escolas e universidades atuam diretamente sobre este funcionamento, tornando-se preciso o constante debate desta temática, objetivando o enfrentamento dos mecanismos de disciplinarização e controle.

A instituição "ensino" aponta a necessidade premente de inventarmos máquinas potentes para a produção de formas autônomas da vida, que caminhem na superação da atual lógica de dominação-servitude (Foucault, 2000a). Isto é ainda mais relevante quando se trata do ensino em saúde, pois requer a formação de um profissional capaz de não se tornar indiferente ao sofrimento e as demandas do outro. É necessária a busca de pluralidade, de afecções nas relações de ensino para que se promova uma elevação das potências de agir.

"Por afeto entendo as afecções do corpo, pelas quais a potência de agir desse corpo é aumentada ou diminuí$\mathrm{da}$, favorecida ou entravada, assim como as ideias dessas afecções" (Espinosa, 1997, p.276). A partir de um conhecimento dos afetos, com exploração daqueles que aumentam a potência de agir (encontros alegres), surge a possibilidade de professores e estudantes dedicarem-se à realização sensível de uma humanidade ainda latente do homem (Rancière , 2014, p.39). Se a subjetivação contemporânea encontra-se implacavelmente ancorada em dispositivos capitalistas, isso não significa o seu aprisionamento absoluto. É sempre possível resistir ao presente, escapar das modelizações dominantes, apropriar-se diferentemente do que nos é oferecido cotidianamente pela televisão, pelo cinema, pelo patrão, pelo cônjuge, pela escola ou pelo outdoor (Soares e Miranda, 2009). Uma vez que "esse desenvolvimento da subjetividade capitalística traz imensas possibilidades de desvio e singularização" (Guattari, \& Rolnik, 1999).
Em suma, é sempre possível atrever-se a singularizar (Guattari e Rolnik, 1999, Deleuze e Guattari, 2012), o campo da saúde fornece diversas possibilidades para isso e necessita que os profissionais tenham esta produção de singularização do cuidado em sua prática clínica e política.

\section{CONCLUSÃO}

O regime disciplinar hegemônico tenta reger a multiplicidade dos homens buscando redundá-los em corpos individuais a serem vigiados, treinados, utilizados e, inclusive, eventualmente punidos.

Neste sentido, conclui-se que é necessário o investimento em dispositivos que produzam um ensino em saúde comprometido com modos de vida livres, em seu sentido ético-estético, a fim de que o profissional de saúde cuide com seu corpo pensamento e seu corpo sensível.Investir em processos de formação éticos e versáteis permite a qualificação das práticas de cuidado, sobretudo, para lidar com as dimensões humanas mais singulares de maneira sofisticada e para uma realização genuína do encontro com o outro.

A limitação deste texto encontra-se na abordagem à conjuntura econômica das insituições de ensino, recomendando-se estudos posteriores que articulem o ensino estético com a própria teoria do capital humano, uma vez que isto interfere diretamente com a possibilidade ou com a dificuldade de criação de novas formas de ensino.

\section{IMPLICAÇÕES PARA A PRÁTICA CLÍNICA}

Considera-se que o ensino sensível, o conhecimento afetivo e a compreensão da importância da vida em comum são fundamentais para o enfrentamento da força disciplinar silenciadora, para alcance de maiores níveis de produção de liberdade no ensino e para a formação de profissionais que produzam um cuidado ético e cidadão.

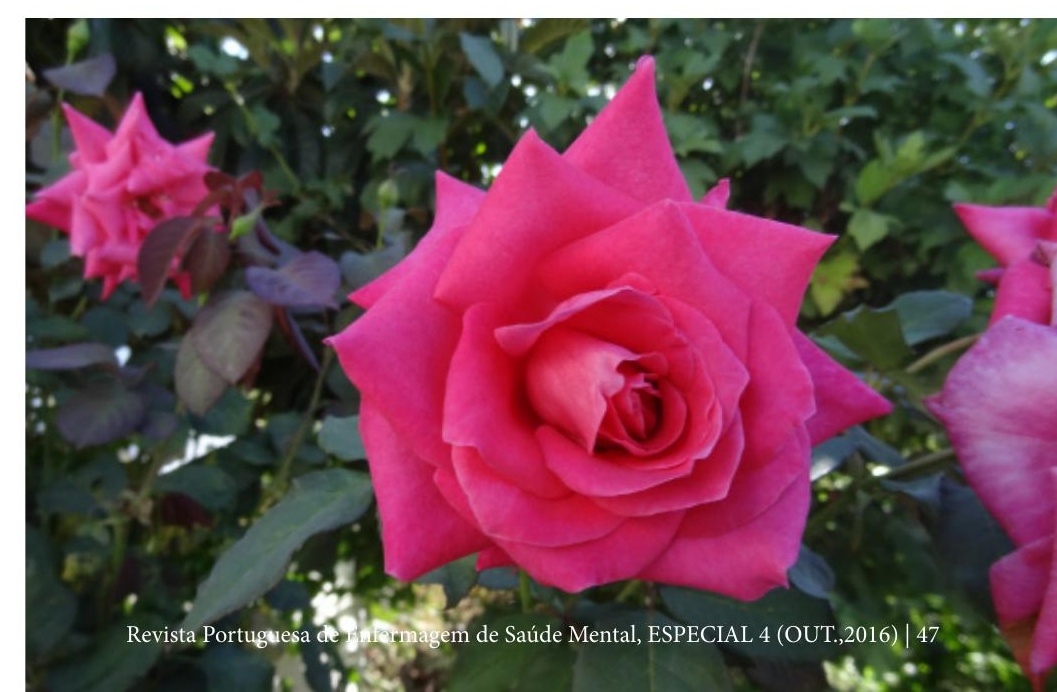




\section{REFERÊNCIAS BIBLIOGRÁFICAS}

Deleuze, G., e Guattari, F. (2012). Mil platôs: Capitalismo e esquizofrenia ( $2^{\mathrm{a}} \mathrm{ed}$.). Rio de Janeiro: Editora 34.

Espinosa, B. (1997). Ética: Demonstrada à maneira dos geômetras. Os Pensadores. São Paulo: Nova Cultural.

Foucault, M. (2000a). Vigiar e punir. Nascimento da Prisão (23a ed.). Rio de Janeiro: Vozes.

Foucault, M. (2000b). Microfísica do poder (15 ed.). Rio de Janeiro: Graal.
Guattari, F., e Rolnik, S. (1999). Micropolítica: Cartografias do desejo. Petrópolis: Vozes.

Rancière, J. (2014). A partilha do sensível: Estética e política ( $3^{a}$ ed.). São Paulo: Editora 34.

Soares, L. B., e Miranda, L. L. (2009). Produzir subjetividades: O que significa?. Revista Estudo e Pesquisa em Psicologia, 9(2), 408-424.

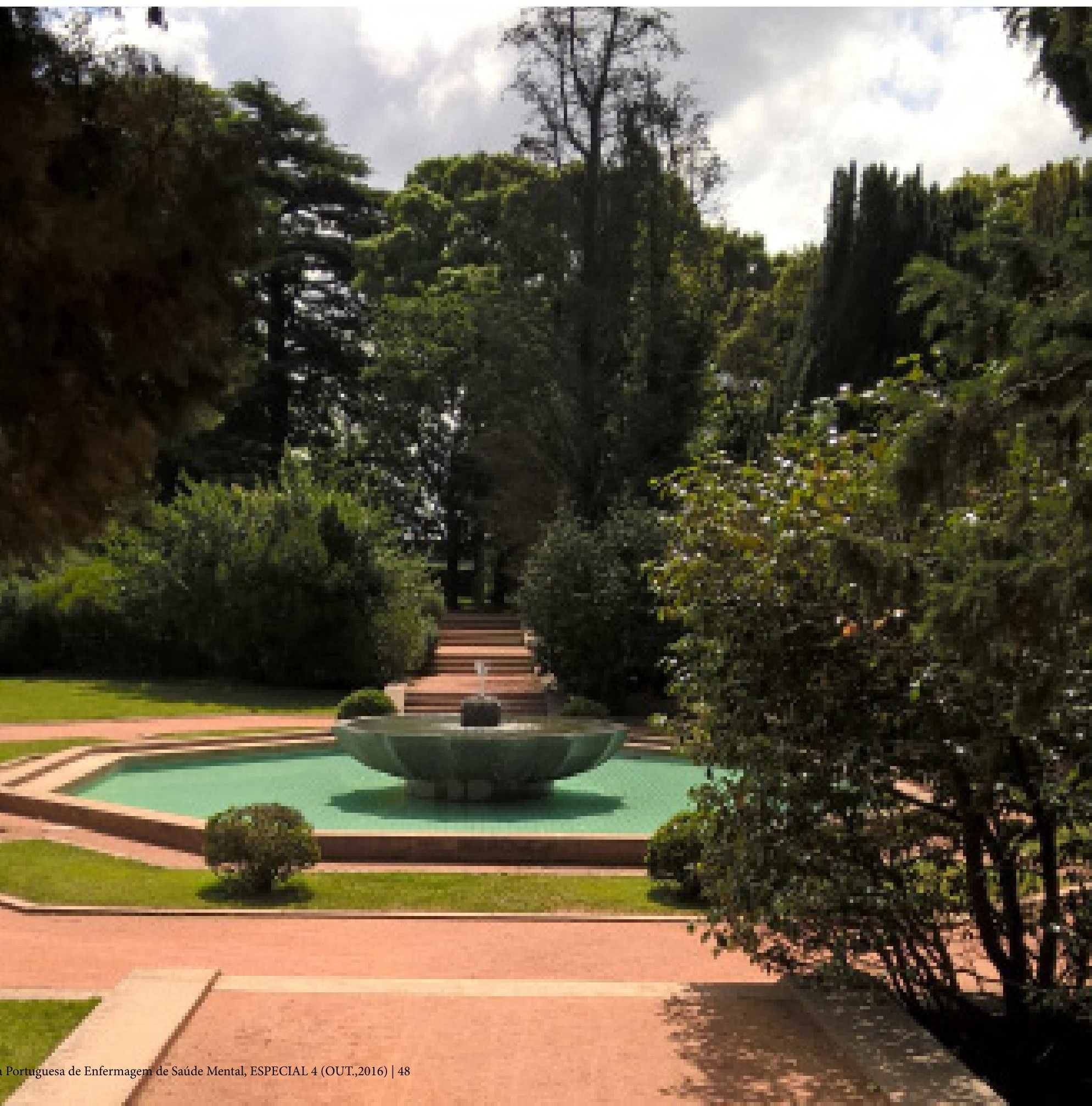

